\title{
Occupational health and safety risk management
}

\author{
Ioan-Florin Oarga ${ }^{1, *}$, Mariana Rațiu ${ }^{2}$, and Ioan-Tudor Oarga ${ }^{3 .}$ \\ ${ }^{1}$ Technical University of Cluj-Napoca, Faculty of Machine Building, 400641 Cluj-Napoca, Romania \\ ${ }^{2}$ University of Oradea, Department of Mechanical Engineering and Automotive, 410087 Oradea, Romania \\ ${ }^{3}$ Technical University of Cluj-Napoca, Faculty of Automation and Computer Science, 400027 Cluj-Napoca, Romania
}

\begin{abstract}
The ongoing industrial revolution also includes the health and safety domain, which assists this development process. The participants and beneficiaries of this revolution don't have to endure a lowering of the protection levels from the beginning of it. Consequently, the health and safety domain needs to play its role in this historical stage. The risks of injury and illness are managed from the beginning, when the technological processes are being developed, on each production stage, until the end of every technological process. In order to achieve this, the professional risks must be identified, quantified, ranked and evaluated such that, the elaborated measures will eliminate or decrease the risks from the source. This control process of occupational health and safety risks of injury or illness uses documents which are applicable to any organization. These documents are legally required in each state, being instruments of the organization management, working like a system along with all other documents.
\end{abstract}

\section{Risk}

We continue to search for the root of the word "risk". A very good synthesis of searches is found on the free encyclopedia Wikipedia [1], which refers to the word "risicu", dating back to Homer's times ( $11^{\text {th }}$ century). "Risicu" was used to describe threats faced by characters. In the $13^{\text {th }}-14^{\text {th }}$ century, the term of commercial risk was used in Italy, after which appeared in France, in the maritime vocabulary ( $17^{\text {th }}$ century). Oxford English Dictionary cites the oldest use of the word "risqué" in 1621.

\subsection{Risk as a concept}

\subsubsection{Risk or the possibility of loss}

The risk is an uncertain event which leads to the possibility of loss, in other words, the occurrence of negative circumstances leading to damage [2]. This future event is used in many areas, starting with commercial, financial, medical, insurance, environment protection, informational, business and last but not least, occupational health and safety.

\subsubsection{Risk measurement}

The quantitative analysis of risk. There are many formal methods provided to measure the risk. This is a necessity to decide the importance of the risk and the costs required to avoid or decrease it.

The probability of an event or a negative act to occur is estimated through the frequency of the last similar events. Often, the risk is measured as an expected value for an unwanted result, described very well with the formula:

\section{$\boldsymbol{R}=\boldsymbol{\Sigma}$ (probability of the event)x(expected loss in the case of the event happening)}

All the cases

Statistically, the function of risk is defined as the expected value of a certain loss depending on the used decision rule to decide in an uncertain situation [3]. This risk value takes in account all the loss possibilities.

\subsection{Occupational health and safety risk}

\subsubsection{Health, safety and environment}

Health, safety and environment are three different domains, but in practice are often tied together. The strongest bond between them is that a single event can impact all three. Over time, different forms of risk analysis were developed to help understand the events and activities leading to human and environment health risks.

\subsubsection{Occupational health and safety}

From occupational health and safety point of view, the term "risk" can be defined as the most probable consequence of a hazard, combined with the risk or occurrence probability. As such, the risk is a function of danger and exposure [4].

\footnotetext{
${ }^{*}$ Corresponding author: florin.oarga@gmail.com
} 


\section{Risk management in occupational health and safety}

\subsection{Occupational health and safety in organizations}

From occupational health and safety point of view, the "risk" is present in all organizations, regardless of their field of activity. This "risk" can be quantified using several methods, with the purpose of measuring it in relation with its occurrence probability and its maximum possible severity. It is true that the magnitude of the risk is directly influenced by the danger degree of the processes which are unfolding in the organization and the probability of an event occurring. The purpose is to decrease the injury and illness risks for the workers involved in the processes conducted by the organization. This risks mitigation is required in all the stages of the organization's operation: technological processes design, equipment acquisition, upgrading production lines, during conversion or upgrade of manufacturing flows, or even during equipment operation. There were cases when the production processes were radically changed, because the specific legislation became very severe from the health and safety point of view, imposing the risk mitigation. In some situations, whole industries have been abandoned, because the required measures to decrease the professional risks were too costly to continue the industrial activity. A relevant example is the asbestos industry and asbestos derived materials.

\subsection{Documents of occupational health and safety system as a part of risk management}

The ongoing industrial revolution also includes the health and safety domain, which assists this development process. The participants and beneficiaries of this revolution don't have to endure a lowering of the protection levels from the beginning of it. In the area of health and safety, everything is centred on identifying the professional injury and illness risks and applying measures to diminish the risks until disposal. Risk management uses a document system applicable to a specific organization. These documents are imposed by legal provisions of all states.

Identification, quantification, ranking and evaluation of occupational health and safety injury and illness risks are an important topic in the economic equation. Taking this in consideration, it is very important that the economic interest should not take precedence over safety considerations at work. This control process of occupational health and safety risks of injury or illness uses documents which are applicable to any organization. These documents are legally required in each state, being instruments of the organization management, working like a system along with all other documents.

In Romania, the legislation governing the occupational health and safety area is based on the provisions of Law 319/14.07.2006 [5] published in Official Monitor no. 646, July $26^{\text {th }}$, 2006. The Law $319 / 2006$ puts into operation the requirements of the
Framework Directive 89/391 [6] for occupational health and safety.

To manage the professional injury and illness risks and to apply health and safety legal provisions, the practice of the organizations led to the development of the documents that met the Romanian and EU legal requirements. These documents should start from authorization of the organization regarding occupational health and safety, before beginning the actual activity. For the situations mentioned in the Law no. 359/08.09.2004 [7], the authorization can be obtained using a simplified procedure, at the moment of registration in the Trade Register of individual persons, family association and legal entities. The proof of this authorization is the Certified Statement, issued under Art. 17 (1)(e) of Law no. $359 / 2004$.

The identification of professional risks for each job is done using the Professional risk exposure sheet, which is filled in by the model required from G.D. no. 355/2007 by the employer, using certain information from each job. When the document is drafted, the leader of the workplace, the assigned worker or the health and safety inspector must participate. Often, human resources representatives participate as well. The next document is the one that quantifies the level of professional risk, using a method of evaluation for the injury or illness risk factors, from the health and safety point of view. This quantification is calculated using the chosen method, which takes in account the four elements of the work system [8]: executor, work task, work means and equipment and work environment by jobs. The evaluation method is chosen by the team responsible for the quantification process of the injury or illness risk. Methods used until this moment operate with statistics, mathematical, graphical and scalar methods, with the purpose of quantifying the risk and comparing it with the minimum, medium and maximum accepted level of workload. This comparison is aiming to offer the management real, concrete information about injury or illness risks, allowing to adopt the right measures of fighting and decreasing them. It is very important to know the fact that the evaluation process of professional injury and illness risks is done every time new technologies, techniques, methods or materials are being introduced in the work process. Also, the evaluation study of professional risks is resumed immediately after a work accident. Fighting and decreasing measures of professional risks are filled in the Prevention and protection plan [9], which has a minimum content imposed by legislation: identified professional risks and fighting measures (technical, organizational, sanitary or other) must be listed [10]. These Prevention and protection plans must keep up with the evolution of processes, technologies and working techniques which take place in an organization. Also, every time something new appears in the production process or a work accident happens, the employer is legally required to adjust the Prevention and protection plans, from the health and safety point of view, and their stipulations need to be introduced in training topics of the staff which participates in the production process. To put into operation the measures stipulated in the Prevention and protection plan, 
occupational health and safety Own Instructions are needed, having the role to complete the legal provisions in the area, taking into account the particularities of activity and enterprise, as well as job particularities and sharing them in the company only after they were approved by the employer [11]. These Own Instructions are included in job specific training topics of each workplace [12]. The topics should contain a training program of each participant to the production processes and testing programs. The participants training is marked in forms, called individual training sheets and have a minimal imposed content [13]. Another way to write down the trainings is the Verbal report of collective training, informing the workers having group activities [14]. These trainings, individual or collective, are completed by occupational health and safety provisions in job descriptions, internal regulations and collective labour agreements, including chapters of occupational health and safety. Their provisions have the role of harmonizing the work tasks, worker's, leader's and employer's health and safety responsibilities, to comply to the provisions of the Prevention and protection plan [15].

Occupational risk management uses measures listed by health and safety documents, the main objective of which is to reduce the risk of injury and illness until elimination. Current practice and legal requirements indicate that the employers should take into account the four elements of the work system, when organizing the activities: executor, work task, work means and equipment and work environment by jobs [16]. To accomplish this, almost always it is necessary to develop a Signalling plan, to complete the informing of the workers and all participants to the production activities [17]. These plans include types of signalling (permanent and occasional) which will be used in the workplace. Most often, they include pictograms (interdiction, warning, compulsory, first aid and emergency situations), acoustic and light signals, trails and markings on the floor, pressured vessels, pipes, code words and gestures. Other present documents in the health and safety area refers to workers equipment, with the purpose of decreasing the risk to which they are exposed [18], the evidence of jobs requiring additional medical exams, or posts with special authorizations. It is imperative to continuously supervise the health status of the workers. Monitoring their status is often the responsibility of specialized medical entities in labour medicine. The management system of occupational risks also includes documents that refer to the technical monitoring of the working equipment, by performing regular inspections and repairs for those that came out of the warranty period or have undergone modifications [19] from their initial state, those that enter the list of work places with serious and/or imminent danger, those entering the I.S.C.I.R. regime, technical equipment books and equipment (in the national language) and the charts of repair/maintenance of the work equipment.

Occupational risk management also includes documents that organize work on health and safety [20] by their own means or by using external services. In this management system, provision should also be made to organize activities during extreme temperatures [21], maternity protection [22], youth protection [23], the organization of mobile and temporary sites [24], the use of hazardous [25], biological [26], carcinogenic or mutagenic substances [27], explosive atmospheres [28].

The documents of the health and safety system as part of the risk management in the health and safety area, are aimed to regulate the activity of this domain in every organization. These documents should comply to the legal requirements and integrate in all documents, to have a systemic effect, with the main goal of decrease to zero the occupational risks.

\section{Conclusion}

Occupational risk management can be realized on every phase of investment, starting with designing of the work process, choosing the materials and working methods. This risk management has as a unique goal the mitigation to zero of the injury or illness risks. To deeply analyze occupational risks, good practice, together with current legal requirements focus on the four elements of the work system: executor, work task, work means and equipment and work environment by jobs. The analysis of occupational risks of injury or illness contains evaluation methods, which are using statistical, mathematical, graphical and scalar methods. Thus, managerial decisions can be oriented more towards one or more elements of the work system and can keep an equilibrum with the desired profit.

Occupational risks management is done using a set of well-defined documents, which are aimed to comply with the legal requirements, working along with all the other documents in an organization. The identification of professional risks for each job is done using the Professional risk exposure sheet. The next document is the one that quantifies the level of professional risk, using a method of evaluation for the injury or illness risk factors, from the health and safety point of view. Fighting and decreasing measures of professional risks are filled in the Prevention and protection plan. These Prevention and protection plans must keep up with the evolution of processes, technologies and working techniques which take place in an organization. To put into operation the measures stipulated in the Prevention and protection plan, occupational health and safety Own Instructions are needed, having the role to complete the legal provisions in the area. These Own Instructions are included in job specific training topics of each workplace. The topics should contain a training program of each participant to the production processes and testing programs. The participants training is marked in forms, called individual training sheets and have a minimal imposed content. The management system of occupational risks also includes documents that refer to the signalling plans, the evidence of jobs requiring additional medical exams, or posts with special authorizations, technical monitoring of the working equipment, by performing regular inspections and repairs for those that came out of the warranty period or have undergone modifications.

These documents are legally required in each state, being instruments of the organization management, 
working like a system along with all other documents. The main goal of decrease to zero the occupational risks.

\section{References}

1. https://ro.wikipedia.org/wiki/Risc\#Etimologie

2. https://en.wikipedia.org/wiki/Oxford_English_Dicti onary

3. https://ro.wikipedia.org/wiki/Risc\#cite_note-2

4. https://ro.wikipedia.org/wiki/Risc\#S\%C4\%83n $\% \mathrm{C} 4$ $\% 83$ tate,_siguran $\% \mathrm{C} 8 \% 9 \mathrm{~B} \% \mathrm{C} 4 \% 83 \% \mathrm{C} 8 \% 99 \mathrm{i}$ me diu

5. Law 319/14.07.2006 published in Official Monitor no. 646, July 26th, 2006 modified by including the modifications and completions of Law no. 51 of March 19th, 2012 and Decision no. 513 of July 4th, 2017

6. Framework Directive $89 / 391$ of June 12th, 1989, on promotion and improvement measures of occupational health and safety

7. Law no. $359 / 8$ Sept 2004 regarding simplification of registration formalities in the Trade Register of individual persons, family association and legal entities, as well as authorization of legal entities, with additional modifications and completions

8. G.D. 1425/2006 with subsequent amendments and completions. Methodological Norm for the Application of Law 319/2006. Art.15 (1)

9. G.D. 1425/2006 with subsequent amendments and completions. Methodological Norm for the Application of Law 319/2006. Secțiunea 7

10. G.D. 1425/2006 with subsequent amendments and completions. Methodological Norm for the Application of Law 319/2006.Art.46 (2)

11. G.D. 1425/2006 with subsequent amendments and completions. Methodological Norm for the Application of Law 319/2006.Art. 15(1)3

12. G.D. with subsequent amendments and completions. Methodological Norm for the Application of Law 319/2006. Art.15 (1)7

13. G.D. 1425/2006 with subsequent amendments and completions. Methodological Norm for the Application of Law 319/2006. Anexa 11
14. G.D. 1425/2006 with subsequent amendments and completions. Methodological Norm for the Application of Law 319/2006. Anexa 12

15. G.D. $1425 / 2006$ with subsequent amendments and completions. Methodological Norm for the Application of Law 319/2006. Art.15 (1)5

16. G.D. $1425 / 2006$ with subsequent amendments and completions. Methodological Norm for the Application of Law 319/2006.Art.15(1)

17. G.D. 971/2006 On minimum requirements for safety and / or health signaling at work. Art.1,5

18. G.D. 1048/2006 on minimum safety and health requirements at work for workers to use personal protective equipment at work

19. G.D. 1146/2006 regarding minimum health and safety requirements for using working equipments by workers

20. G.D. $1425 / 2006$ with additional modifications and completions. Methodological Norm for the Application of Law 319/2006. Chapter III

21. G.E.O. 99/2000 on measures that can be applied in periods of extreme temperatures for the protection of employed persons

22. G.E.O. 96/2003 on the protection of maternity at work

23. O. no. $753 / 2006$ on the protection of young people at work

24. G.D. 300/2006 on minimum safety and health requirements for temporary or mobile construction sites

25. G.D. $1408 / 2008$ on the classification, packaging and labeling of dangerous substances

26. G.D. $1092 / 2006$ on the protection of workers from the risks related to exposure to biological agents at work

27. G.D. 1093/2006 laying down minimum safety and health requirements for the protection of workers from the risks related to exposure to carcinogens or mutagens at work

28. G.D. $1058 / 2006$ on minimum requirements for improving the safety and health protection of workers potentially at risk from explosive atmospheres 